Louisiana State University

LSU Digital Commons

Faculty Publications

Department of Geology and Geophysics

$11-2-2018$

\title{
A general synthesis approach for supported bimetallic nanoparticles via surface inorganometallic chemistry
}

\author{
Kunlun Ding \\ Louisiana State University \\ David A. Cullen \\ Oak Ridge National Laboratory \\ Laibao Zhang \\ Louisiana State University \\ Zhi Cao \\ Institute of Coal Chemistry Chinese Academy of Sciences \\ Amitava D. Roy \\ Louisiana State University
}

See next page for additional authors

Follow this and additional works at: https://digitalcommons.Isu.edu/geo_pubs

\section{Recommended Citation}

Ding, K., Cullen, D., Zhang, L., Cao, Z., Roy, A., Ivanov, I., \& Cao, D. (2018). A general synthesis approach for supported bimetallic nanoparticles via surface inorganometallic chemistry. Science, 362 (6414), 560-564. https://doi.org/10.1126/science.aau4414

This Article is brought to you for free and open access by the Department of Geology and Geophysics at LSU Digital Commons. It has been accepted for inclusion in Faculty Publications by an authorized administrator of LSU Digital Commons. For more information, please contact ir@lsu.edu. 


\section{Authors}

Kunlun Ding, David A. Cullen, Laibao Zhang, Zhi Cao, Amitava D. Roy, Ilia N. Ivanov, and Dongmei Cao 


\title{
A general synthesis approach for supported bimetallic nanoparticles via surface inorganometallic chemistry
}

\author{
Kunlun Ding ${ }^{*}$, David A. Cullen ${ }^{2}$, Laibao Zhang ${ }^{1}$, Zhi Cao ${ }^{3}$, Amitava D. Roy $^{4}$, Ilia N. Ivanov ${ }^{5}$, \\ Dongmei $\mathrm{Cao}^{6}$.
}

${ }^{1}$ Department of Chemical Engineering, Louisiana State University, Baton Rouge, LA 70803, USA.

${ }^{2}$ Materials Science and Technology Division, Oak Ridge National Laboratory, Oak Ridge, TN 37831, USA.

${ }^{3}$ State Key Laboratory of Coal Conversion, Institute of Coal Chemistry, Chinese Academy of Sciences, Taiyuan, Shanxi 030001 \& Synfuels China Beijing, 100195, P. R. China.

${ }^{4}$ Center for Advanced Microstructures \& Devices, Louisiana State University, Baton Rouge, LA 70806, USA.

${ }^{5}$ Center for Nanophase Materials Sciences, Oak Ridge National Laboratory, Oak Ridge, Tennessee 37831, USA.

${ }^{6}$ Shared Instrumentation Facility, Louisiana State University, Baton Rouge, LA 70803, USA.

*Correspondence to: kunlunding@1su.edu

\begin{abstract}
The synthesis of ultrasmall supported bimetallic nanoparticles (between 1 and 3 nanometers in diameter) with well-defined stoichiometry and intimacy between constituent metals remains a substantial challenge. We synthesized ten different supported bimetallic nanoparticles via surface inorganometallic chemistry by decomposing and reducing surfaceadsorbed heterometallic double complex salts, which are readily obtained upon sequential adsorption of target cations and anions on a silica substrate. For example, adsorption of $\mathrm{Pd}\left(\mathrm{NH}_{3}\right)_{4}{ }^{2+}$ followed by adsorption of $\mathrm{PtCl}_{4}{ }^{2-}$ was used to form PdPt nanoparticles. These supported bimetallic nanoparticles show enhanced catalytic performance in acetylene selective hydrogenation, which clearly demonstrate a synergistic effect between constituent metals.
\end{abstract}


One Sentence Summary: Rational assembly of heterometallic double complex salts provides a versatile platform for the synthesis of well-defined supported bimetallic nanoparticles. 
Heterogeneous catalysts that contain bimetallic nanoparticles (NPs) are used in many petrochemical processes, including reforming (1), selective hydrogenation $(2,3)$ and dehydrogenation (4), and acetoxylation (5). In recent years, bimetallic NPs have been used in biomass conversions (6), electrocatalysis (7-10), and many other catalytic processes (11-13). The difference in catalytic properties of bimetallic NPs compared with their parent metals, originates from their distinct geometric and electronic structures as well as the synergistic effects between the two metals $(6,14-16)$. In particular, synthetic protocols have been demonstrated crucial to the structural, electronic, and hence catalytic performance of bimetallic NPs. Conventional impregnation method usually results in ill-defined bimetallic NPs with inhomogeneous particle sizes and compositions $(17,18)$. New strategies for the synthesis of bimetallic NPs include colloidal synthesis (19), surface organometallic chemistry (20), atomic layer deposition (21), coadsorption and coreduction of metal cations (18), and carbothermal shock synthesis (22). Nevertheless, the synthesis of ultrasmall $(<3 \mathrm{~nm})$ supported bimetallic NPs with well-defined stoichiometry and intimacy between constituent metals remains challenging.

We explored the preparation of supported bimetallic NPs by reducing heterometallic double complex salts (DCSs) precursors (e.g. $\left.\left[\mathrm{Pd}\left(\mathrm{NH}_{3}\right)_{4}\right]\left[\mathrm{PtCl}_{4}\right]\right)$, which differ from conventional precursors in that the stoichiometry and intimacy of two metals are already established. Although DCSs have received tremendous interest in the study of inorganometallic coordination compounds $(23,24)$, their poor solubility greatly hinders their applications in many fields $(23,25-27)$. Limited success has been achieved in the synthesis of supported bimetallic catalysts using DCS precursors. Boellaard et al. (28) described a synthesis of supported Ni-Fe catalysts from double complex salts by mixing two precursors in solution in the presence of a support. Due to the lack of interaction between bulk DCSs and the catalyst support, the deposition of DCSs on the surface of support is less controllable. Rather than depositing DCSs from solution, we show that heterometallic DCSs can be synthesized directly on a substrate by sequential adsorption of complex metal cations and anions (Fig. 1A). The supported DCSs with precisely paired metal cations and anions through electrostatic interactions can be converted to well-defined supported bimetallic NPs upon reduction. This approach eliminates the issue of competitive adsorption of different metal cations in the coadsorption and coreduction methods (18), on the other hand, it also overcomes the solubility issues of DCSs for the bimetallic catalyst synthesis. It can be applied to a large variety of bimetallic NPs, including several bulk 
immiscible systems. The bimetallic NPs are extremely small (1 to $3 \mathrm{~nm}$ ) and have narrow size distributions $( \pm 25 \%)$, and their bimetallic nature was confirmed by single-NP elemental analysis. These bimetallic catalysts outperform their parent metals in selective hydrogenation of acetylene.

The adsorption of metal cations were carried out on silica $(18,29)$ [see Supplementary Materials (SM)]. A porous silica support (figure S1) was first dispersed in water, and the $\mathrm{pH}$ of the solution was adjusted to 9 to obtain a negatively charged silica surface. After the adsorption of complex metal cations, e.g. $\mathrm{Pd}\left(\mathrm{NH}_{3}\right)_{4}{ }^{2+}$, silica was then separated from the mother solution, washed with copious water, and dried before the adsorption of metal anions. Our initial attempt for the subsequent anion adsorption using an aqueous solution led to the formation of either large aggregates (figure S2) or monometallic complexes (figure S3). This failure was likely caused by nonnegligible solubility of DCSs in water, that led to dissolution, ripening, or leaching of DCSs. Alternatively, we adopted an aprotic solvent dichloromethane and introduced quaternary ammonium cations to assist dissolution (figures S4 to S6). Complex metal anions in dichloromethane can precisely target the multivalvent metal cations preadsorbed on silica to form supported heterometallic DCSs. Further reducing these silica-supported DCSs under a flow of $\mathrm{H}_{2} / \mathrm{N}_{2}(\mathrm{v} / \mathrm{v}=1 / 9)$ mixture at $400^{\circ} \mathrm{C}$ afforded the desired silica-supported bimetallic NPs.

Figure 1B shows high-angle annular dark-field scanning transmission electron microscopy (HAADF-STEM) images of ten types of supported bimetallic NPs synthesized by this approach. Large-area transmission electron microscopy (TEM) and HAADF-STEM images and size distributions of these samples are shown in figures S7 to S16. These NPs are mostly smaller than $3 \mathrm{~nm}$ in diameter and uniformly dispersed on the silica support. These NPs are smaller than most bimetallic NPs from colloidal synthesis (19), but slightly bigger than these synthesized by coadsorption and coreduction method (18). The polydispersities are similar to the latter. The bimetallic nature of these NPs was confirmed by single-NP energy-dispersive X-ray spectroscopy (EDS) analysis. The composition of several individual NPs was also obtained for each sample, as well as large-area EDS analysis to obtain an average composition of each sample (quantification results are shown in Tables S1 to S10). In all cases, the single-NP analysis confirmed the NPs are bimetallic. Further, the average composition from the single-NP analysis was generally consistent with the average composition provided by large-area EDS analysis, suggesting that the supported DCSs precursors were evenly decomposed into bimetallic NPs. 
The bulk phase diagrams of the Cu-Ir, Pd-Ir, and Pt-Ir systems indicate that these metal pair are immiscible below $800^{\circ} \mathrm{C}(30)$. Interestingly, these systems still form bimetallic NPs with metal ratios near 1. Aberration-corrected HAADF-STEM images of $\mathrm{Cu}-\mathrm{Ir} / \mathrm{SiO}_{2}$ and $\mathrm{Pd}-\mathrm{Ir} / \mathrm{SiO}_{2}$ show uneven contrast within single NPs (figures S17 and S18), suggesting the occurrence of intraparticle phase segregation at a subnanometer level. This type of nanoscopic phase segregation has been reported in several bimetallic systems, including $\mathrm{Cu}-\mathrm{Ir}(31), \mathrm{Ru}-\mathrm{Pd}(32)$, and Pt-Ni (33). The lack of macroscopic phase segregation in M-Ir systems may be partially attributed to the extremely high melting point of Ir metal, which may prevent the nanoscopically phase segregated NPs from coarsening.

In order to validate our proposed surface inorganometallic chemistry for the bimetallic NPs synthesis, we used x-ray photoelectron spectroscopy (XPS) to study the structural evolution of the surface intermediates during the synthesis. The XPS results are shown in Fig. 2 and figures S19 to S27. After the adsorption of complex metal cations $\left(\mathrm{Pd}\left(\mathrm{NH}_{3}\right)_{4}{ }^{2+}, \mathrm{Pt}\left(\mathrm{NH}_{3}\right)_{4}{ }^{2+}\right.$, and $\mathrm{Ru}\left(\mathrm{NH}_{3}\right)_{6}{ }^{2+}$ ), the XPS signals of metals and nitrogen were observed (Fig. 2, and figures S19 and $\mathrm{S} 23$ ). Weak Cl 2p signals were also observed on these samples (figure S25), indicating that the divalent complex metal cations require an extra $\mathrm{Cl}^{-}$ion to balance the excess positive charge. After the adsorption of complex metal anions $\left(\mathrm{PtCl}_{4}{ }^{2-}, \mathrm{IrCl}_{6}{ }^{2-}\right.$, and $\left.\mathrm{AuCl}_{4}{ }^{-}\right)$, the intensity of $\mathrm{Cl} 2 \mathrm{p}$ signal increased along with the appearance of Pt, Ir, and Au signals, confirming the successful adsorption of complex metal anions.

In addition to the $\mathrm{N} 1 \mathrm{~s}$ signal from the $\mathrm{NH}_{3}$ ligand $(400 \mathrm{eV})$, a new $\mathrm{N}$ 1s signal was observed at $402 \mathrm{eV}$ on the nonreduced $\left[\mathrm{Pd}\left(\mathrm{NH}_{3}\right)_{4}\right]\left[\mathrm{PtCl}_{4}\right] / \mathrm{SiO}_{2},\left[\mathrm{Pd}\left(\mathrm{NH}_{3}\right)_{4}\right]\left[\mathrm{IrCl}_{6}\right] / \mathrm{SiO}_{2}$, $\left[\mathrm{Pt}\left(\mathrm{NH}_{3}\right)_{4}\right]\left[\mathrm{IrCl}_{6}\right] / \mathrm{SiO}_{2}$, and $\left[\mathrm{Ru}\left(\mathrm{NH}_{3}\right)_{4}\right]\left[\mathrm{IrCl}_{6}\right] / \mathrm{SiO}_{2}$ samples (Fig. 2 and figure S23) from the $\mathrm{N}$ atom in the quaternary ammonium cation, which was used to assist the dissolution. The adsorption of quaternary ammonium cations was required to balance the excess negative charge of the divalent complex anions. No quaternary ammonium cation was needed when a monovalent anion, $\mathrm{AuCl}_{4}^{-}$, was used, and in this case, the $\mathrm{N} 1 \mathrm{~s}$ signal at $402 \mathrm{eV}$ was absent for the nonreduced $\left[\mathrm{Pd}\left(\mathrm{NH}_{3}\right)_{4}\right]\left[\mathrm{AuCl}_{4}\right] / \mathrm{SiO}_{2}$ sample (Fig. 2).

Since the adsorption of complex metal anions was carried out in an aprotic solvent, dichloromethane, ion pairs should mostly stay associated and form dipoles. Therefore, the adsorption of complex metal anions may not be solely driven by electrostatic interactions. 
Additionally, dipole-dipole and dipole-induced dipole interactions between the anionic complex and the surface may also play important roles. The surface chemistry described here works well for silica surface but may not be simply extended to other types of support. For instance, alumina has higher point of zero charge compared to silica (18). Thus, complex metal anions are normally adopted for the synthesis of alumina-supported noble metal catalysts. Extending our synthesis strategy to alumina support may require substantial efforts on solvent engineering of metal precursors. Furthermore, one should be aware that chloride binds strongly to the alumina surface and may change the surface properties.

The metallophilic interaction between the adsorbed complex metal cations and anions was confirmed by ultraviolet-visible (UV-Vis) diffuse reflectance spectroscopy, indicating the formation of supported DCSs. DCSs usually exhibit distinct colors originating from their metalmetal interactions; many DCSs are named after their colors, e.g. Magnus' green salt $\left[\mathrm{Pt}\left(\mathrm{NH}_{3}\right)_{4}\right]\left[\mathrm{PtCl}_{4}\right]$, and Vauquelin's pink salt $\left[\mathrm{Pd}\left(\mathrm{NH}_{3}\right)_{4}\right]\left[\mathrm{PdCl}_{4}\right](23)$. Because of the relatively low loadings, the supported complex species obtained by our sequential adsorption approach do not exhibit noticeable colors. Nevertheless, the supported $\left[\mathrm{Pd}\left(\mathrm{NH}_{3}\right)_{4}\right]\left[\mathrm{PtCl}_{4}\right] / \mathrm{SiO}_{2}$ synthesized by sequential adsorption shows identical UV-Vis absorption bands $(315,390$, and $535 \mathrm{~nm})$ with bulk DCS $\left[\mathrm{Pd}\left(\mathrm{NH}_{3}\right)_{4}\right]\left[\mathrm{PtCl}_{4}\right]$, which exhibits a pink color $(34,35)$. In contrast, the UV-Vis spectra of the impregnated $\mathrm{Pd}\left(\mathrm{NH}_{3}\right)_{4} \mathrm{Cl}_{2} / \mathrm{SiO}_{2}$ and $\mathrm{K}_{2} \mathrm{PtCl}_{4} / \mathrm{SiO}_{2}$ were different from the spectra of $\left[\mathrm{Pd}\left(\mathrm{NH}_{3}\right)_{4}\right]\left[\mathrm{PtCl}_{4}\right] / \mathrm{SiO}_{2}$.

The amorphous nature of supported DCSs was confirmed by electron microscopy studies. No NPs were observed on the supported DCSs initially (Fig. 3A). However, within 2 min of electron beam exposure, many NPs in the 1 to $2 \mathrm{~nm}$ size range were observed, indicating the in situ decomposition of DCSs associated with the electron beam damage. Extended x-ray absorption fine structure (EXAFS) measurements of $\mathrm{Ir} \mathrm{L}_{\mathrm{III}}$-edge were performed in order to study the structural evolution of coordination sphere of Ir atoms. As shown in Fig. 3B, the EXAFS spectra of nonreduced $\left[\mathrm{Ru}\left(\mathrm{NH}_{3}\right)_{6}\right]\left[\mathrm{IrCl}_{6}\right] / \mathrm{SiO}_{2}$ and $\left[\mathrm{Pd}\left(\mathrm{NH}_{3}\right)_{4}\right]\left[\mathrm{IrCl}_{6}\right] / \mathrm{SiO}_{2}$ were similar to that of the $\mathrm{Na}_{2} \mathrm{IrCl}_{6} \cdot 6 \mathrm{H}_{2} \mathrm{O}$ reference. The major peak between 1.5 to $2.5 \AA$ we associated with the $\mathrm{Ir}-\mathrm{Cl}$ bond in $\mathrm{IrCl}_{6}{ }^{2-}$. After the reduction of $\left[\mathrm{Ru}\left(\mathrm{NH}_{3}\right)_{6}\right]\left[\mathrm{IrCl}_{6}\right] / \mathrm{SiO}_{2}$ at $400^{\circ} \mathrm{C}$ under a hydrogen atmosphere, a new peak appeared between 2.5 to $3 \AA$, corresponding to $\mathrm{Ir}-\mathrm{M}(\mathrm{M}=\mathrm{Ru}$ or Ir) bonds. XPS analysis of the reduced $\mathrm{DCSs} / \mathrm{SiO}_{2}$ samples confirmed the reduction of metal 
atoms into metallic states (figures S20 and S22). Further, the disappearance of $\mathrm{N} 1 \mathrm{~s}$ and $\mathrm{Cl} 2 \mathrm{p}$ signals indicated the successful removal of ligands (figures S24, S26, and S27).

The catalytic performance of the supported bimetallic NPs was evaluated for acetylene hydrogenation under noncompetitive conditions (figures S28 to S30). The bimetallic catalysts ( $\mathrm{Pd}-\mathrm{Ir} / \mathrm{SiO}_{2}, \mathrm{Pd}-\mathrm{Pt} / \mathrm{SiO}_{2}, \mathrm{Pd}-\mathrm{Au} / \mathrm{SiO}_{2}, \mathrm{Pt}-\mathrm{Ir} / \mathrm{SiO}_{2}$, and $\mathrm{Ru}-\mathrm{Pt} / \mathrm{SiO}_{2}$ ) generally showed higher catalytic activity and lower alkane selectivity compared to their parent metals. $\mathrm{Ru}-\mathrm{Ir} / \mathrm{SiO}_{2}$ was an exception, in that it showed the same negligible activity as its parent metals. Among the group VIII metals, Ru and Ir often showed the strongest binding strengths for many types of adsorbates (36), which might explain the low activity of $\mathrm{Ru} / \mathrm{SiO}_{2}, \mathrm{Ir} / \mathrm{SiO}{ }_{2}$, and $\mathrm{Ru}-\mathrm{Ir} / \mathrm{SiO}_{2}$ in acetylene hydrogenation. The enhanced activity and suppressed ethane selectivity of bimetallic $\mathrm{Pd}-\mathrm{M} / \mathrm{SiO}_{2}$ and $\mathrm{Pt}-\mathrm{M} / \mathrm{SiO}_{2}$ compared to their parent metals, could be partly attributed to the relatively weaker binding strengths of acetylene and ethylene on these bimetallic NPs $(2,3)$.

We further studied Pd-Pt bimetallic NPs with different compositions in acetylene hydrogenation under competitive conditions (Figs. 4A and 4B, figures S31 to S33). The compositions of supported Pd-Pt bimetallic NPs were adjusted by coadsorption of complex metal cations followed by adsorption of complex metal anions. For instance, equal molar $\mathrm{Pd}\left(\mathrm{NH}_{3}\right)_{4}{ }^{2+}$ and $\mathrm{Pt}\left(\mathrm{NH}_{3}\right)_{4}{ }^{2+}$ cations were coadsorbed on $\mathrm{SiO}_{2}$, followed by adsorption of $\mathrm{PdCl}_{4}{ }^{2-}$ or $\mathrm{PtCl}_{4}{ }^{2-}$ anions and subsequent reduction, yielding $\left(\mathrm{Pd}_{0.5} \mathrm{Pt}_{0.5}\right)-\mathrm{Pd} / \mathrm{SiO}_{2}$ or $\left(\mathrm{Pd}_{0.5} \mathrm{Pt}_{0.5}\right)-\mathrm{Pt} / \mathrm{SiO}_{2}$, respectively (figure S34). Compared to the monometallic $\mathrm{Pd} / \mathrm{SiO}_{2}$ and $\mathrm{Pt} / \mathrm{SiO}_{2}$, the three bimetallic catalysts prepared by sequential adsorption method, $\left(\mathrm{Pd}_{0.5} \mathrm{Pt}_{0.5}\right)-\mathrm{Pd} / \mathrm{SiO}{ }_{2},\left(\mathrm{Pd}_{0.5} \mathrm{Pt}_{0.5}\right)$ $\mathrm{Pt} / \mathrm{SiO}_{2}$, and $\mathrm{Pd}-\mathrm{Pt} / \mathrm{SiO}_{2}$, all showed enhanced catalytic activity and suppressed alkane selectivity in acetylene hydrogenation in the presence of high concentration propylene. Moreover, three bimetallic catalysts were prepared by coadsorption and coreduction of $\mathrm{Pd}\left(\mathrm{NH}_{3}\right)_{4}{ }^{2+}$ and $\mathrm{Pt}\left(\mathrm{NH}_{3}\right)_{4}{ }^{2+}$ cations (figure S35) (18), $\mathrm{Pd}_{0.25} \mathrm{Pt}_{0.75} / \mathrm{SiO}_{2}, \mathrm{Pd}_{0.5} \mathrm{Pt}_{0.5} / \mathrm{SiO}_{2}$, and $\mathrm{Pd}_{0.75} \mathrm{Pt}_{0.25} / \mathrm{SiO}_{2}$, which showed lower activity than a physical mixture of $\mathrm{Pd} / \mathrm{SiO}_{2}$ and $\mathrm{Pt} / \mathrm{SiO}_{2}$, and their alkane selectivity is greater than those prepared by sequential adsorption method.

IR spectroscopy with $\mathrm{CO}$ as a probe molecule was used to study the surface properties of these monometallic and bimetallic catalysts (Fig. 4C). We found that the bridge CO peak was very sensitive to the type of metals $\left(1920 \mathrm{~cm}^{-1}\right.$ and $1790 \mathrm{~cm}^{-1}$ for Pd and Pt surfaces, respectively). Interestingly, the IR spectra of $\mathrm{Pd}_{0.5} \mathrm{Pt}_{0.5} / \mathrm{SiO}_{2}$ catalyst prepared by coadsorption 
method exhibits a Pt-like feature, whereas the $\mathrm{Pd}-\mathrm{Pt} / \mathrm{SiO}_{2}$ catalyst prepared by sequential adsorption method exhibits a Pd-like feature. This suggests that the surfaces of the bimetallic NPs prepared by coadsorption and sequential adsorption methods are Pt-rich and Pd-rich, respectively. The superior intrinsic activity of $\mathrm{Pd}$ and the electronic modification by $\mathrm{Pt}$ underneath might be the origin of the improved catalytic performance of the $\mathrm{Pd}-\mathrm{Pt} / \mathrm{SiO}_{2}$ catalyst prepared by sequential adsorption method.

\section{References and Notes:}

1. J. H. Sinfelt, Structure of Bimetallic Clusters. Acc. Chem. Res. 20, 134-139 (1987).

2. G. Kyriakou et al., Isolated Metal Atom Geometries as a Strategy for Selective Heterogeneous Hydrogenations. Science 335, 1209-1212 (2012).

3. F. Studt et al., Identification of non-precious metal alloy catalysts for selective hydrogenation of acetylene. Science 320, 1320-1322 (2008).

4. J. J. H. B. Sattler, J. Ruiz-Martinez, E. Santillan-Jimenez, B. M. Weckhuysen, Catalytic Dehydrogenation of Light Alkanes on Metals and Metal Oxides. Chem. Rev. 114, 1061310653 (2014).

5. M. S. Chen, D. Kumar, C. W. Yi, D. W. Goodman, The promotional effect of gold in catalysis by palladium-gold. Science 310, 291-293 (2005).

6. D. M. Alonso, S. G. Wettstein, J. A. Dumesic, Bimetallic catalysts for upgrading of biomass to fuels and chemicals. Chem. Soc. Rev. 41, 8075-8098 (2012).

7. B. Lim et al., Pd-Pt Bimetallic Nanodendrites with High Activity for Oxygen Reduction. Science 324, 1302-1305 (2009).

8. C. Chen et al., Highly Crystalline Multimetallic Nanoframes with Three-Dimensional Electrocatalytic Surfaces. Science 343, 1339-1343 (2014).

9. X. Q. Huang et al., High-performance transition metal-doped $\mathrm{Pt}_{3} \mathrm{Ni}$ octahedra for oxygen reduction reaction. Science 348, 1230-1234 (2015).

10. L. Z. Bu et al., Biaxially strained $\mathrm{PtPb} / \mathrm{Pt}$ core/shell nanoplate boosts oxygen reduction catalysis. Science 354, 1410-1414 (2016).

11. J. K. Edwards et al., Switching Off Hydrogen Peroxide Hydrogenation in the Direct Synthesis Process. Science 323, 1037-1041 (2009).

12. S. J. Freakley et al., Palladium-tin catalysts for the direct synthesis of $\mathrm{H}_{2} \mathrm{O}_{2}$ with high selectivity. Science 351, 965-968 (2016). 
13. N. Agarwal et al., Aqueous Au-Pd colloids catalyze selective $\mathrm{CH}_{4}$ oxidation to $\mathrm{CH}_{3} \mathrm{OH}$ with $\mathrm{O}_{2}$ under mild conditions. Science 358, 223-226 (2017).

14. N. Toshima, T. Yonezawa, Bimetallic nanoparticles - novel materials for chemical and physical applications. New J. Chem. 22, 1179-1201 (1998).

15. R. Ferrando, J. Jellinek, R. L. Johnston, Nanoalloys: From theory to applications of alloy clusters and nanoparticles. Chem. Rev. 108, 845-910 (2008).

16. M. Sankar et al., Designing bimetallic catalysts for a green and sustainable future. Chem. Soc. Rev. 41, 8099-8139 (2012).

17. O. S. Alexeev, B. C. Gates, Supported bimetallic cluster catalysts. Ind. Eng. Chem. Res. 42, 1571-1587 (2003).

18. A. Wong, Q. Lin, S. Griffin, A. Nicholls, J. R. Regalbuto, Synthesis of ultrasmall, homogeneously alloyed, bimetallic nanoparticles on silica supports. Science 358, 1427-1430 (2017).

19. K. D. Gilroy, A. Ruditskiy, H. C. Peng, D. Qin, Y. N. Xia, Bimetallic Nanocrystals: Syntheses, Properties, and Applications. Chem. Rev. 116, 10414-10472 (2016).

20. J. P. Candy, B. Didillon, E. L. Smith, T. B. Shay, J. M. Basset, Surface Organometallic Chemistry on Metals - a Novel and Effective Route to Custom-Designed Bimetallic Catalysts. J. Mol. Catal. 86, 179-204 (1994).

21. J. L. Lu et al., Toward atomically-precise synthesis of supported bimetallic nanoparticles using atomic layer deposition. Nat. Commun. 5, (2014).

22. Y. G. Yao et al., Carbothermal shock synthesis of high-entropy-alloy nanoparticles. Science 359, 1489-1494 (2018).

23. J. Bremi et al., From Vauquelin's and Magnus' salts to gels, uniaxially oriented films, and fibers: Synthesis, characterization, and properties of tetrakis(1-aminoalkane)metal(II) tetrachlorometalates(II). Chem. Mater. 11, 977-994 (1999).

24. L. H. Doerrer, Steric and electronic effects in metallophilic double salts. Dalton Trans. 39, 3543-3553 (2010).

25. D. I. Potemkin et al., Preferential CO oxidation over bimetallic Pt-Co catalysts prepared via double complex salt decomposition. Chem. Eng. J. 207, 683-689 (2012).

26. D. I. Potemkin et al., Silica, alumina and ceria supported $\mathrm{Au}-\mathrm{Cu}$ nanoparticles prepared via the decomposition of $\left[\mathrm{Au}(\mathrm{en})_{2}\right]_{2}\left[\mathrm{Cu}\left(\mathrm{C}_{2} \mathrm{O}_{4}\right)_{2}\right]_{3} \cdot 8 \mathrm{H}_{2} \mathrm{O}$ single-source precursor: Synthesis, characterization and catalytic performance in CO PROX. Catal. Today 235, 103-111 (2014). 
27. S. T. Thompson, H. H. Lamb, Catalysts for selective hydrogenation of furfural derived from the double complex salt $\left[\mathrm{Pd}\left(\mathrm{NH}_{3}\right)_{4}\right]\left(\mathrm{ReO}_{4}\right)_{2}$ on gamma- $\mathrm{Al}_{2} \mathrm{O}_{3}$. J. Catal. 350, 111-121 (2017).

28. E. Boellaard, A. M. van der Kraan, J. W. Geus, Preparation, reduction and CO chemisorption properties of cyanide-derived $\mathrm{Ni}_{\mathrm{x}} \mathrm{Fe} / \mathrm{Al}_{2} \mathrm{O}_{3}$ catalysts. Appl. Catal. A-Gen. 224, $1-20$ (2002).

29. L. Jiao, J. R. Regalbuto, The synthesis of highly dispersed noble and base metals on silica via strong electrostatic adsorption: I. Amorphous silica. J. Catal. 260, 329-341 (2008).

30. ASM HandBook Volume 3 - Alloy Phase Diagrams. (ASM International, 1992).

31. F. L. Wang et al., Solid-Solution Alloy Nanoparticles of the Immiscible Iridium-Copper System with a Wide Composition Range for Enhanced Electrocatalytic Applications. Angew. Chem. Int. Ed. 57, 4505-4509 (2018).

32. K. Kusada et al., Solid Solution Alloy Nanoparticles of Immiscible Pd and Ru Elements Neighboring on Rh: Changeover of the Thermodynamic Behavior for Hydrogen Storage and Enhanced CO-Oxidizing Ability. J. Am. Chem. Soc. 136, 1864-1871 (2014).

33. Z. Q. Niu et al., Anisotropic phase segregation and migration of $\mathrm{Pt}$ in nanocrystals en route to nanoframe catalysts. Nat. Mater. 15, 1188-1194 (2016).

34. J. R. Miller, Metal-metal interactions in square-planar complexes. J. Chem. Soc., 4452-4457 (1961).

35. J. R. Miller, The metal-metal interaction in Magnus's green salt and related compounds. $J$. Chem. Soc. 0, 713-720 (1965).

36. F. Abild-Pedersen et al., Scaling properties of adsorption energies for hydrogen-containing molecules on transition-metal surfaces. Phys. Rev. Lett. 99, (2007).

37. K. Nakanishi, Pore Structure Control of Silica Gels Based on Phase Separation. J. Porous Mater. 4, 67-112 (1997).

38. K. L. Ding et al., Highly Efficient Activation, Regeneration, and Active Site Identification of Oxide-Based Olefin Metathesis Catalysts. ACS Catal. 6, 5740-5746 (2016).

39. B. Ravel, M. Newville, ATHENA, ARTEMIS, HEPHAESTUS: data analysis for X-ray absorption spectroscopy using IFEFFIT. J. Synchrotron Rad. 12, 537-541 (2005).

Acknowledgments: We thank Dr. Spivey for the access to IR instrument and Dr. Dooley for the assistance in thermogravimetric and nitrogen sorption analysis. Dr. Thomas Blanchard is acknowledged for ICP analysis. Funding: K.D. acknowledges the startup funding from 
Louisiana State University. Electron microscopy and UV-Vis spectroscopy were conducted at the Center for Nanophase Materials Sciences, which is a DOE Office of Science User Facility. X-ray photoelectron spectroscopy was performed at the Shared Instrumentation Facility (SIF) at Louisiana State University. The Ketek ${ }^{\mathrm{TM}}$ seven-element detector array used in this study for X-ray measurements at CAMD was acquired with funds provided by The Louisiana Board of Regents (LEQSF(2016-17)-ENH-TR-07). Author contributions: K.D. conceived the concept, designed the experiments, synthesized and characterized the nanoparticles, performed catalytic tests, and wrote the paper; D.A.C. performed HAADF-STEM and single-NP EDS characterization; L.Z. carried out IR, TGA, XRD, and nitrogen sorption measurements; Z.C. assisted with data analysis and manuscript preparation; A.D.R. carried out EXAFS measurements; I.N.I. carried out UV-Vis measurements; D.C. performed XPS characterization. Competing interests: K.D. has filed provisional patent application no. 62/721,690 regarding the synthesis of supported bimetallic nanoparticles via double complex salts. Data and materials availability: All data is available in the main text or the supplementary materials.

\section{Supplementary Materials:}

Materials and Methods

Tables S1-S11

References 37-39 
Fig. 1. Schematic illustration and electron microscopy analysis of the supported bimetallic NPs. (A) A schematic illustration of the "Surface Inorganometallic Chemistry" for the synthesis of supported bimetallic NPs. (B) HAADF-STEM images of ten types of supported bimetallic NPs synthesized by this approach. All scale bars are $10 \mathrm{~nm}$.

Fig. 2. XPS and UV-Vis spectra of supported DCSs and reference compounds. The structure of $\left[\mathrm{Pd}\left(\mathrm{NH}_{3}\right)_{4}\right]\left[\mathrm{PtCl}_{4}\right] / \mathrm{SiO}_{2}$ is illustrated on the right. The absorption bands associated with the metallophilic interaction between Pd and Pt metal centers are marked by dashed lines.

Fig. 3. Structural evolution of supported DCSs upon reduction. (A) HAADF-STEM images of nonreduced $\left[\mathrm{Ru}\left(\mathrm{NH}_{3}\right)_{6}\right]\left[\mathrm{IrCl}_{6}\right] / \mathrm{SiO}_{2}$ synthesized by sequential adsorption. (B) Fourier transforms of EXAFS spectra of various Ir-containing samples at the Ir $\mathrm{L}_{\mathrm{III}}$-edge: $\mathrm{Na}_{2} \mathrm{IrCl}_{6} \bullet 6 \mathrm{H}_{2} \mathrm{O}$ reference; nonreduced $\left[\mathrm{Ru}\left(\mathrm{NH}_{3}\right)_{6}\right]\left[\mathrm{IrCl}_{6}\right] / \mathrm{SiO}_{2}$ and $\left[\mathrm{Pd}\left(\mathrm{NH}_{3}\right)_{4}\right]\left[\mathrm{IrCl}_{6}\right] / \mathrm{SiO}_{2}$, and reduced $\mathrm{Ru}-$ $\mathrm{Ir} / \mathrm{SiO}_{2}$ synthesized by sequential adsorption.

Fig. 4. Catalysis and IR studies of the supported bimetallic NPs. (A and B) Catalytic performance of supported monometallic and bimetallic NPs in acetylene hydrogenation. (C) IR spectra of $\mathrm{CO}$ molecule adsorbed on various catalysts. $\mathrm{Pd}-\mathrm{Pt} / \mathrm{SiO}$ and $\mathrm{Pd}_{0.5} \mathrm{Pt}_{0.5} / \mathrm{SiO}_{2}$ are synthesized by sequential adsorption (this work) and coadsorption (Ref. 18) methods, respectively. All catalysts were reduced at $400^{\circ} \mathrm{C}$. Experimental details are given in the Supplementary Materials. 